\title{
Well - Being Therapy (WBT) for Depression
}

\author{
Majid Moeenizadeh \\ Faculty of Education and Psychology, Ferdowsi University of Mashhad, Iran \\ E-mail: moinyzadeh@gmail.com
}

Kiran Kumar K. Salagame

Department of Studies in Psychology, University of Mysore

Mysore 570006, India

E-mail: kiku@psychology.uni-mysore.ac.in

\begin{abstract}
In clinical psychology, Well-Being Therapy (WBT) is a relatively modern technique of managing patients with depression. Well Being Therapy is based on Ryff's multidimensional model of psychological well-being. Fava has developed and validated it in a number of randomized controlled trials. The findings indicate that positive evaluation of one's self, sense of continued growth and development is possible by specific intervention. The objective of this therapy is to increase the level of psychological well-being of patients and decrease vulnerability to depression. WBT can be executed in 8 to 10 sessions according to Fava's phases. Method: Sample of 40 patients was treated by WBT (20) and CBT (20) and was assessed for the level of psychological well-being (PWB) before and after the interventions. Results: ANOVA showed significant difference between pre and post treatment scores and WBT is more effective than CBT. Conclusions: The results suggested the feasibility and clinical advantages of adding WBT to repertoire of the treatment techniques.
\end{abstract}

Keywords: Positive Psychology, Well-Being, Well-Being Therapy (WBT), Psychological Well-Being (PWB) and Depression

\section{Introduction}

Contemporarily psychological well-being is understood not only as the absence of mental disorder but also as the presence of positive psychological resources. That includes components of hedonic or subjective well-being (e.g., positive affect, life satisfaction, happiness) as well as components of eudemonic well-being (e.g., self-acceptance, positive relations, autonomy, purpose in life) (Ryan \& Deci, 2001). The concept of wellbeing is applied to more and more studies in clinical and non-clinical psychology, which has lead to the formal foundation of a new field called Positive Psychology (Seligman \& Csikszentmihalyi, 2000). Hitherto Psychology has been mainly working within a disease model. Strong emphasis has been laid on discovering deficiencies in human behavior and determining ways of repairing this damage. The focus of psychologists has been solely on taking away something negative instead of adding something positive (Seligman, 2002). Most researches focus on the psychotherapeutic strategies, which lead to decline in symptoms of a disorder. It is found to be impressive for cognitive behavioral therapies (Fava \& Sonino, 2000).

This situation has been changing since the advent of positive psychology. The investigations in positive psychology lay stress on the importance of helping clients to realize their strengths (Lutsky, 2003). Investigators have focused on developing strategies aimed at enhancement of positive affect and effectiveness both in nonclinical and clinical settings (Sin \& Lyubomirsky, 2009), and psychotherapeutic strategies have as their goal enhancement of well-being instead of reducing the symptoms (Giovanni, Fava, \& Tomba, 2009). The approaches to increase well-being are generically termed as "positive psychology interventions" (PPIs), which refer to treatment methods or intentional activities that aim to cultivate positive feelings, behaviors, or cognitions (Sin \& Lyubomirsky, 2009). Diverse PPI strategies such as writing gratitude letters, practicing optimistic thinking, replaying positive experiences, and socializing have been shown to increase well-being in nonclinical samples (e.g., Fordyce, 1977; Lyubomirsky, 2008; Ruini, Belaise, Brombin, Caffo, \& Fava, 2006). Sin and Lyubomirsky (2009) also point out that programs, interventions, or treatments aimed at fixing, remedying, or healing something that is pathological or deficient — as opposed to building strengths — do not fit the definition of a PPI. 


\section{Well- Being Therapy and its rationale}

Well-being therapy is one of the PPI strategies aimed at building strengths in clinical population recently developed by Giovanni Fava, an Italian psychotherapist with his colleagues ( Fava, Rafanelli, Grandi, Conti, \& Belluardo, 1998; Fava, Rafanelli, Cazzaro, Conti, \& Grandi, 1998a; Fava, 1999; Fava, et al., 2001; Fava \& Ruini, 2003; Fava, et al., 2005; Giovanni, Fava, \& Tomba, 2009). Well-being therapy is based on an educational model which is structured, directive, and oriented to present problems and situation (Fava, 1999; Fava \& Ruini, 2003). It is a short-term psychotherapeutic strategy that can be implemented over 8-12 sessions, every week or alternate weeks. Well-Being Therapy involves 'technique of self observation' along with the 'use of a structured diary' and 'interaction between patients and therapist'. According to Fava, the therapy sessions are divided into three phases -initial, intermediate and final (for details see section 3.4 on Procedure).

Although PPIs may be an option for treating a variety of mental disorders (e.g., anxiety disorders; Fava et al., 2005), they can be particularly useful for addressing a paucity of positive affect, engagement, and life meaning that characterize depression (Forbes \& Dahl, 2005; Seligman, Rashid, \& Parks, 2006). As practitioners advice PPIs can be used in the treatment of both clinically depressed and non-depressed clients. As Fava points out PPIs are especially effective for treating residual symptoms (Fava, et al., 1998), and avert future relapse for formerly depressed clients (Seligman, et al., 2006).

The development of well-being therapy originated from three converging developments. First, there is a growing body of literature on residual symptoms after apparently successful treatment in mood and anxiety disorders. Such symptoms may include anhedonia and impaired functional capacity. Most residual symptoms also occur in the prodromal phase of illness and may progress to become prodromes of relapse (Fava, Tomba, \& Grandi, 2007). The recognition of residual symptomatology has led to psychotherapeutic treatment specifically addressed to residual symptomatology, which was found to improve the long-term outcome of major depressive disorders (Fava, et al., 2005).

Second, the partial remission after treatment was not found to be limited to negative affective symptoms. Remitted patients with mood and anxiety disorders displayed significantly lower levels of psychological well-being as measured by the Psychological Well Being Scales (Ryff, 1989) compared with healthy control subjects (Rafanelli, et al., 2000). The question then arose as to whether such impairment is also amenable to improvement with psychological treatment.

Finally, clinicians working with patients with mood and anxiety disorders are often confronted with the unsatisfactory degree of remission that current therapeutic strategies yield and with the vexing problems of relapse and recurrence (Fava, et al., 2007).

Major clinical trials have emphasized the fact that full remission occurs in a minority of patients. The need to advance intervention strategies and programs to foster psychological well-being has become pressing. These intervention strategies are crucial in clinical populations with high risk for relapse, such as in major depression. Therefore, an intervention that targets the positive may address an aspect of functioning and health that is typically left unaddressed in conventional treatments. A theory-based resilient approach differs from other approaches to treatment in that it contains emphasis on positive emotional health rather than focusing on decreasing negative affective symptoms. The model also presumes that deficits in well-being are due to inattention to positive experiences and lack of capacity to sustain states of well-being due to automatic thoughts (Fava, et al., 2007). Well-being Therapy was developed in this context. The rationale behind well-being therapy is that criteria can be established to distinguish valid and helpful positive thinking from unrealistic expectations and that promotion of psychological well-being may result in decrease of distress and higher levels of resilience to environmental circumstances.

Well-being therapy differs from standard cognitive therapies, in the following ways. A main difference is the focus, which in well-being therapy is on instances of emotional well-being, whereas in cognitive therapy it is on psychological distress. The second important distinction is that in cognitive therapy, the goal is abatement of distress through automatic thought control or contrast, whereas in well-being therapy the goal is promotion of psychological well-being along Ryff's (1989) dimensions. The final distinction is that, unlike cognitive behavioral frameworks, well-being therapy refrains from explaining from the outset, to the patient its rationale and strategies but relies on his or her progressive appraisals of positive self. Enhancing acceptance (vs. control) of distress and positive resources to keep distress in bounds and fostering individualized road to recovery, set by the patient's increasing awareness, is another characteristic of well-being therapy (Giovanni, et al., 2009).

The objective of this study is to apply a novel psychotherapeutic approach to increase the level of well-being in persons suffering from depression. This study is also going to find out which of the two, Cognitive Behavior 
Therapy (CBT) or Well-Being Therapy (WBT), has better effect on persons with depression. In other words, the study is to examine the relative efficacy of CBT and WBT, in terms of reduction of symptoms and enhancement of well-being.

\section{Methodology}

\subsection{Design}

A pre-test and post-test design was used to find the differences between CBT and WBT groups. The independent variable was the therapeutic aspects of WBT and CBT and the dependent variable was the condition of patients suffering from depression measured with reference to symptoms of depression and level of psychological well-being.

\subsection{Sample}

Adolescent and adult students suffering from depression who visited Ferdowsi University Clinic and other affiliated clinics, in Mashhad, Iran were studied. Psychiatrists in the clinics were requested to introduce the patients who suffer from Dysthymic disorders according to DSM IVR criteria and the patients who were not prescribed drugs by psychiatrists. Thus, the inclusion criteria is only the Dysthymic patients who have low mood, fatigue, hopelessness, trouble concentrating and problems of appetite and sleep. Only those patients in the range of 20 and 40 years were considered. The exclusion criterion was all other kinds of depressive disorders. Forty male and female patients were chosen for the study, using (Krejcie \& Morgan, 1970) criteria for stratified random sampling. The criteria stipulates the sample size needed, when estimating a population percentage (or proportion) at $95 \%$ confidence level and $\mathrm{a}+$ or -5 percent point confidence. The subjects (20 male and 20 female, who were in the age range of 20 to 40 years (Mean=24.37 and $\mathrm{SD}=2.24$ ) were randomly assigned to either WBT or CBT. Attempt was made to match the two groups with respect to demographic factors like gender, age, educational level and socio-economic status (see table 1,2 and 3).

\subsection{Tools}

Three tests - Psychological Well-being Scale (PWB) (Ryff, 1989), The Persian-language version of the second edition of this instrument (BDI-II) (Ghasemzadeh, Mojtabai, Karamghadiri \& Ebrahimkhani, 2005) and Rorschach Inkblot Test (Rorschach, 1921) were administered to patients by the researcher, before and after the intervention. The research data was collected for Ph.D. thesis using all of them. Nevertheless, this paper reports the findings related to psychological well-being as measured by Ryff's scale.

The 84-items scale was devised to evaluate six dimensions of the well-being: (1) autonomy, (2) environmental mastery, (3) personal growth, (4) positive relationships with others, (5) purpose in life and (6) self-acceptance. Each dimension was measured with 14 items. The original 20 -item per scale version of the Scales of Psychological Well Being was validated in a community based sample of 321 men and women from multiple age groups (Ryff, 1989a). Analyses revealed that each of the six scales had high levels of internal consistency with alpha coefficients ranging from .86 to .93 . Test-retest reliability (over 6 weeks) was acceptable, ranging from $.81-.88$ for the six scales. The scales also showed good construct validity, significantly correlating with Bradburn's Affect Balance Scale (correlation coefficients ranged from .25 to .62) and Neugarten's Life Satisfaction Index (correlation coefficients ranged from .26 to .73) (all $\mathrm{p}<.001$ ), and Rosenberg's Self-Esteem Scale (correlation coefficients ranged from .36 to $.62, \mathrm{p}<.001$ ). This scale was translated into Persian by the researcher and was utilized. The reliability was calculated ( $\mathrm{N}=30$ students) and Chronbach $\alpha$ is .967.

\subsection{Procedure}

Three tests were carried out in two sessions for each patient. Immediately after completion of the pre-assessment, the therapy sessions commenced. The therapy was conducted according to convenience of the patients. Per day a minimum of one and a maximum of three patients were treated either with WBT or with CBT depending upon to which group they were assigned.

Well-Being Therapy: (a) Initial Phase -The first two sessions in the initial phase, are simply concerned with identifying and setting episodes of well-being into situational context, no matter how short-lived they are. Patients are requested to maintain report in the form of a structured diary, the circumstances surrounding the episodes of well-being, rated on a scale of 0 to 100, with zero being absence of well-being and 100 being the most intense well-being. The patients are encouraged to monitor the quality of experience people associated with daily situations (work, leisure, etc.). This initial phase extends over a couple of sessions. Its duration depends on the factors that affect homework assignment, such as resistance and compliance. Identification of instances of well-being and of optimal experiences and reporting them in the diary would be the indicators that the individual is ready to move to the next phase, which aims to target the obstacles to sustained psychological well-being. 
(b) Intermediate Phase - In the 3rd to 5th sessions the patients are encouraged to identify thoughts. Once the instances of well-being are properly recognized, the patient is encouraged to identify thoughts and beliefs leading to premature interruption of well-being. This phase is crucial because it allows the therapist to identify the areas of psychological well-being which are unaffected by irrational or automatic thoughts and which are saturated with them. The therapist may challenge these thoughts with appropriate questions, such as, "what is the evidence for or against this idea?" or "Are you thinking in all-or-none terms?" (Beck, Rush, Shaw, \& Emery, 1979) The therapist may also reinforce and encourage activities that are likely to elicit wellbeing and optimal experiences (e.g., assigning the task of undertaking particular pleasurable activities for a certain time each day). Such reinforcement may also result in graded task assignments (Beck, et al., 1979), with special reference to exposure to feared or challenging situations, which the patient is likely to avoid.

The focus of this phase of well-being therapy is always on self-monitoring of moments and feelings of well-being and graded task assignments. The therapist refrains from suggesting conceptual and technical alternatives (e.g., different interpretations), unless a satisfactory degree of self observation (including irrational or automatic thoughts) has been achieved. Attention is paid to the ratings assigned by the patient to moments of well-being associated with carrying out the assignment. If the ratings are consistently low (e.g., 30 out of 100), it is necessary for the therapist to lead the patient to explain what potentially represents a rating of 70 or 80 . This is done to avoid having the patient focus exclusively on circumstances associated with lower levels of hedonia. This intermediate phase may extend over two or three sessions, depending on the patient's motivation and ability, and it paves the way for the specific well-being enhancing strategies. Identification of automatic thoughts in the diary indicates readiness of the patient to move to the next phase, aimed at offering alternative interpretations to automatic thoughts.

(c) Final Phase - In the 6th to 8th sessions the patients are able to readily identify moments of well-being. They also are aware of interruptions to well-being feelings, and follow optimal experiences. Encountering the challenge that optimal experiences may entail is emphasized. The monitoring of the course of episodes of well-being allows the therapist to realize specific impairments in well-being dimensions according to Ryff's conceptual framework. Ryff's six dimensions of psychological well-being are progressively introduced to the patients, as long as the material that is recorded lends itself to it. For example, the therapist could explain that autonomy consists of possessing an internal locus of control, independence, and self-determination, or that personal growth consists of being open to new experience and considering self as expanding over time, if the patient's attitudes show impairments in these specific areas. Errors in thinking and alternative interpretations are then discussed. Now, the patient is expected to be able to readily identify moments of well-being, be aware of interruptions to well being feelings (cognitions), and to follow optimal experiences. Meeting the challenge that optimal experiences may entail is emphasized. The follow up on the course of episodes of well-being allows the therapist to recognize specific impairments in well-being dimensions according to Ryff's conceptual framework. Therefore the goal of the therapist is to guide the patient from an impaired level to an optimal level according to the above six dimensions.

\section{Cognitive Behavior Therapy: Standard CBT techniques developed by Arnold Beck were used.}

Both WBT and CBT were conducted for eight sessions of an average of 45 minutes duration. The first two sessions were conducted in the same week. The remaining six sessions were conducted spread over a period of six weeks (one session per week). The total duration of therapy for each patient was seven weeks.

All the patients were reassessed after treatment by the researcher on all the three tests.

\section{Results}

The obtained data were analyzed using Repeated Measures ANOVA. The obtained results are represented in the form of tables and charts. On the measure of psychological well-being, there are significant differences in pre and post scores for $\mathrm{CBT}$ group $(\mathrm{N}=20$, Mean of pre $\mathrm{CBT}=219.20, \mathrm{SD}=54.67$ and Mean of post $\mathrm{CBT}=366.35$, $\mathrm{SD}=7.57)$ and WBT group $(\mathrm{N}=20$, Mean of Pre $\mathrm{WBT}=187, \mathrm{SD} 26.15$ and Mean of post $\mathrm{WBT}=449.85, \mathrm{SD}=17.92)$ as $F(7258.937)$ and $p$ value (.001) indicate (see Table 4, 5). When the Cohen's Effect Size (Cohen, J. 1988) is calculated for pre-post CBT and WBT (see Table 6), it is found that WBT has greater effect than CBT.

When the six dimensions of PWB Inventory was also subjected to Repeated Measures ANOVA separately, it was found that the two therapy groups showed significant differences in all of them (Table 5 and Chart 1). Out of the six dimensions, in four - autonomy, environmental mastery, purpose in life and self-acceptance there were greater differences between the two groups, with patients in WBT group having higher scores. (Table 5 and Chart 1). 
The correlation between post BDI and post PWB scores was calculated. Pearson correlation shows (see Table 7) that there is a significant negative relationship $(\mathrm{r}=-.570, \mathrm{p}=0.000)$ between well-being and depression, which means that when well-being increases depression decreases. It indicates that well-being increased after treatment by WBT.

\section{Discussion}

The illness ideology is disproved by positive psychology, as it is more concerned with finding what has to be changed than how it has to be changed. The important use of ideology of positive psychology in clinical psychology occurs in its widened view of what are the important aspects of human behavior and what we need to comprehend to bring about quality in the life of people. Positive clinical psychology is not just identifying the weaknesses and treating or preventing disorders. It also involves identifying human strengths and raising mental health, unlike the negative clinical psychology which is based on the illness ideology (Maddux \& Lopez, 2004). Therefore, it is time that illness ideology is substituted with positive ideology of the psychology of health, happiness and human assets.

As Maddux (2004) states, the intervention of positive psychology lays stress on the improvement of strengths and assets of the patients in addition to, and at times instead of enhancement of their weakness and shortages. It is guided by the belief that strengthening the strengths will weaken the weaknesses. Deeply rooted in the illness ideology's concept of psychological health and illness, is a categorical model in which individuals are resolved to have or not to have a dysfunction that is, to be either psychologically well or psychologically ill. On the other hand, there are alternative dimensional models, which presuppose the presence of normality and abnormality, wellness and illness, effectual and ineffectual psychological performance in a continuous sequence. In this dimensional approach, the so-called psychological disorder variants are simply the extremes of normal psychological phenomena and ordinary problems (Keyes, 2002). As Lubinski, (2000) states, the dimensional model does not deal with classifying people or disorders but it is concerned with identifying and measuring individual differences in psychological phenomena such as emotion, mood, intelligence, and personal styles. The differences in the individuals on the dimensions of their interests are anticipated, such as the differences we find in formal test of the intelligence.

As evident from the findings of this study all, the patients who underwent WBT and CBT have gained significantly. The gain is more in WBT group as compared to CBT group. In four of the six dimensions of PWB, the patients who were treated with WBT have shown a significant increase in well-being indicating the efficacy of this novel technique. They are autonomy, environmental mastery, purpose in life, and self-acceptance. Autonomy represents the capacity of a person to be independent in thought and action. Therefore, the patients who are concerned about expectations and evaluations of other people may lean on judgment of others to make important decisions and so on. However, after therapy according to this research finding they learned to be independent and continued their work by self-determination. When their thought and action changed, they will able to resist social pressures, regulate behavior from within and evaluate self by personal standards.

Gain in scores on environment mastery reflected the depressed patients' enhanced sense of control over the external world, their confidence in manipulating the environment, enhanced awareness of the opportunities, and the ability to choose contexts suitable for their personal needs and values. This is opposite of the sense of helplessness that is characteristic of depressed patients.

Purpose in life is another dimension in which the patients showed significant differences. Depressed patients are known to feel hopelessness and worthlessness, which are related to a lack of sense of meaning in life, having few or no goals or aims, a lack of sense of direction, not seeing purpose in past life, having no future outlook or belief that give life a meaning. The scores of the patients in this study indicate that after therapy they have overcome the typical symptoms of a depressed state and have moved towards a positive view of life and feel hopeful, confident, optimistic, and purposeful.

Feeling worthless, negative self-image, increased sense of guilt, increased sense of dissatisfaction, dejection, etc., characterize a depressed person. Increase in self-acceptance score of PWB among patients in WBT group is a definite indication that patients after therapy developed a positive attitude toward the self; accepted their good and bad qualities; and felt positive about their past life. The findings of this investigation lend support to previous findings reviewed in detail elsewhere (Ruini \& Fava, 2009) suggesting that treating with WBT instead of treating with CBT may be more effective in enhancing well-being and also reduce depression.

The rationale for emphasis on identifying positive experiences derives from both early formulations of and empirical data highlighting the value of ameliorating hedonic deficits. Meehl described how people "with low hedonic capacity should pay greater attention to the 'hedonic book keeping' of their activities than would be 
necessary for people located midway or high on the hedonic capacity continuum (Meehl, 1975). That is, it matters more to someone cursed with an inborn hedonic defect whether he is efficient and sagacious in selecting friends, jobs, cities, tasks, hobbies, and activities in general"' (p. 305). Meehl's observations have been confirmed in two controlled trials, where attention to positive daily experiences resulted in improving the levels of psychological well-being (Emmons \& McCullough, 2003) or health center visits for illness (Burton \& King, 2004).

Studies have shown that individuals invest their attention and psychic resources in activities associated with rewarding and challenging states of consciousness, in particular with optimal experience (Csikszentmihalyi \& Csikszentmihalyi, 1998). Optimal experience is characterized by the perception of high environmental challenge and environmental mastery, deep concentration, involvement, enjoyment, control of the situation, clear-cut feedback on the control on the course of activity, and intrinsic motivation (Deci \& Ryan, 1985). Patients are thus asked to report whether they feel optimal experiences in their daily life and are invited to list the associated activities or situations.

Arguments about quality of life and assessment of happiness have continued, up to this time. For instance, Aristotle as a great thinker distinguished between pleasure and good life. Aristotle differentiated between hedonism (the life occupied by the search for pleasure) and eudemonia (happiness that arises from good work). Contemporary psychologists followed him and have suggested that modern well-being research comes in two conceptual camps: hedonics, which focuses on how the person feels about his or her life, and eudemonics, which focuses on living a life in full accord with one's potential (Ryan \& Deci, 2001). However, Argyle \& Crossland, (1987) mentioned that early pioneers were never concerned with the difference between eudemonia and hedonia. However, Ryan and Deci, (2001) have suggested that there is a line demarcating these two historical views of happiness as they might apply to modern research paradigms. Kashdan, Biswas-Diener and King (2008) have also stated that there is as much worth in the empirical study of the similarities and complementarities of hedonic and eudemonic models of well-being as there are examining differences.

However, the eudemonic model appears to be much more feasible because it is related to human potential and personal strength (Ryff \& Singer, 1996). Ryff's model of psychological well-being, encompassing autonomy, personal growth, environmental mastery, purpose in life, positive relations and self-acceptance especially has been found to fit into specific impairments of patients with affective disorders (Rafanelli, et al., 2000; Ruini \& Fava, 2002). The developments of this element paved way for well-being enhancing psychotherapeutic strategies in clinical medicine.

Limitations: Perhaps the greatest limitation of this study relates to follow up of the patients. Follow up could not be conducted because some of them study in last semester and after finishing returned to their city and they could not be traced easily. Additionally some of them declined to give any information about their place of residence. Another limitation is that the sample in this study consisted only students and hence the findings cannot be generalized to other population. Further, the sample of this study was limited to only those suffering from dysthymic depressive disorder and we do not know how patients suffering from other kinds of depression disorder respond to WBT.

\section{Conclusion}

Well-being therapy is based on inferences arrived at from the Positive Psychology literature. The objective of WBT is to achieve optimal level of well - being by helping patients to realize their true potential. As is evident, WBT is still at evolving stage. The article has employed this method to examine the effectiveness of WBT for treatment of patients suffering from depression. The result has shown considerable reduction in depression disorder by enhancing well-being.

\section{References}

Argyle, M., \& Crossland, J. (1987). The dimensions of positive emotions. Br J Soc Psychol, 26 (Pt 2), $127-137$.

Beck, A. T., Rush, A. J., Shaw, B. F., \& Emery, G. (1979). Cognitive therapy of depression. New York: Guilford Press.

Burton, C. M., \& King, L. A. (2004). The health benefits of writing about intensely positive experience. Journal of Research in Personality, 38, 150-163.

Cohen, J. (1988). Statistical power analysis for the behavioral sciences (2nd ed.). Hillsdale, NJ: Erlbaum.

Csikszentmihalyi, M., \& Csikszentmihalyi, I. (1998). Optimal experience psychological studies of flow in consciousness. New York: Cambridge University Press. 
Deci, E. L., \& Ryan, R. M. (1985). Intrinsic motivation and self-determination in human behavior. New York: Plenum.

Emmons, R. A., \& McCullough, M. E. (2003). Counting blessings versus burdens. Personality and Social Psychology, 84, 377-389.

Fava, G. A. (1999). Well-being therapy: conceptual and technical issues. Psychother Psychosom, 68(4), 171-179.

Fava, G. A., \& Mangelli, L. (2001). Assessment of subclinical symptoms and psychological well-being in depression. Eur Arch Psychiatry Clin Neurosci, 251 Suppl 2, II47-52.

Fava, G. A., \& Ruini, C. (2003). Development and characteristics of a well-being enhancing psychotherapeutic strategy: well-being therapy. J Behav Ther Exp Psychiatry, 34(1), 45-63.

Fava, G. A., \& Sonino, N. (2000). Psychosomatic medicine: emerging trends and perspectives. Psychother Psychosom, 69(4), 184-197.

Fava, G. A., \& Tomba, E. (2009). Increasing Psychological Well-Being and Resilience by Psychotherapeutic Methods. J Pers.

Fava, G. A., Rafanelli, C., Cazzaro, M., Conti, S., \& Grandi, S. (1998a). Well-being therapy. Psychol. Med, 28, 475-480.

Fava, G. A., Rafanelli, C., Grandi, S., Conti, S., \& Belluardo, P. (1998). Prevention of recurrent depression with cognitive behavioral therapy: preliminary findings. Arch Gen Psychiatry, 55(9), 816-820.

Fava, G. A., Ruini, C., Rafanelli, C., Finos, L., Salmaso, L., Mangelli, L., et al. (2005). Well-being therapy of generalized anxiety disorder. Psychother Psychosom, 74(1), 26-30.

Fava, G. A., Tomba, E., \& Grandi, S. (2007). The road to recovery from depression. Psychotherapy and Psychosomatics, 76, 260-265.

Forbes, E., \& Dahl, R. (2005). Neural systems of positive affect: Relevance to understanding child and adolescent depression. Development and Psychopathology, 17, 827-850.

Fordyce, M. W. (1977). Development of a program to increase happiness. Journal of Counseling Psychology, 24, 511-521.

Ghassemzadeh, H., Mojtabai, R., Karamghadiri, N., \& Ebrahimkhani, N. (2005). Psychometric properties of a persian language version of the Beck Depression Inventory (2 ed). BDI-II persian. Depression and anxiety, (pp.1-7). Wiley-Liss, Inc.

Giovanni, A., Fava, G. A., \& Tomba, E. (2009). Increasing psychological well-being and resilience by psychotherapeutic methods. Journal of Personality, 77.

Kashdan, T. B., Biswas-Diener, R., \& King, L. A. (2008). Reconsidering happiness: the costs of distinguishing between hedonics and eudaimonia Journal of Positive Psychology. 3, 219-233.

Keyes, C. L. M. (2002). Complete mental health: An agenda for the 21 st century. In C.L.M.K Keyes \& J. Haidt (Eds), Flourishing: positive psychology and the life well-being. Washington, Dc: American psychological Association.

Krejcie, R. V., \& Morgan, D. W. (1970). Determining Sample Size for Research Activities. Educational and Psychological Measurement, 30, 607-610.

Lubinski, D. (2000). Scientific and social significance of assessing individual differences: "sinking shafts at a few critical points". Annu Rev Psychol, 51, 405-444.

Lutsky, N. (2003). Positive Psychology. Psychology; 382 Syllabii (Fall 2003), [Online] Available: http://www.acad.carleton.edu/curricular/PSYC/classes/psych382_Lutsky.

Lyubomirsky, S. (2008). The how of happiness: a scientific approach to getting the life you want. New York: Penguin Press.

Maddux, S., \& Lopez, S. J. (2004). Toward a positive clinical psychology: Deconstruction the Illness Ideology and constructing an Ideology of Human Strengths and potential. In P. A. L. a. S. Joseph (Ed.), Positive Psychology In Practice. Hoboken, New Jersey: John Wiley \& Sons, Inc.

Meehl, P. E. (1975). Hedonic capacity: Some conjectures. Bulletin of the Menninger Clinic, 39, 295-307.

Rafanelli, C., Park, S. K., Ruini, C., Ottolini, F., Cazzaro, M., \& Fava, G. A. (2000). Rating well-being and distress. Stress Medicine, 16, 55-61. 
Rorschach, H. (1921). Psychodiagnostik; methodik und ergebnisse eines wahrnehmungsdiagnostischen experiments (deutenlassen von zufallsformen). Bern und Leipzig: E. Bircher.

Ruini, C., \& Fava, G. A. (2002). Panic and depression. Am J Psychiatry, 159(4), 681; author reply 681-682.

Ruini, C., Belaise, C., Brombin, C., Caffo, E., \& Fava, G. A. (2006). Well-being therapy in school settings: a pilot study. Psychother Psychosom, 75(6), 331-336.

Ryan, R. M., \& Deci, E. L. (2001). On happiness and human potentials: a review of research on hedonic and eudaimonic well-being. Annu Rev Psychol, 52, 141-166.

Ryff, C. D. (1989). Happiness is everything, or is it? Explorations on the meaning of psychological well-being. Personality and social psychology, 6, 1069-1081.

Ryff, C. D. (1989a). Happiness is everything, or is it? Exploration on the meaning of psychological well-being. personality and social psychology, 57, 1069-1081.

Ryff, C. D., \& Singer, B. (1996). Psychological well-being: meaning, measurement, and implications for psychotherapy research. Psychother Psychosom, 65(1), 14-23.

Seligman, M. E. P. (2002). Positive psychology, positive prevention and positive therapy. In C. R. S. S. J. Lopez (Ed.), Handbook of positive psychology (pp. 3-9). New York: Oxford University Press.

Seligman, M. E. P., \& Csikszentmihalyi, M. (2000). positive psychology: An introduction. American Psychologist, 55, 5-14.

Seligman, M., Rashid, T., \& Parks, A. (2006). Positive psychotherapy. American Psychologist, (Nov) PP.774-788.

Sin, N. L., \& Lyubomirsky, S. (2009). Enhancing well-being and alleviating depressive symptoms with positive psychology interventions: a practice-friendly meta-analysis. J Clin Psychol, 65(5), 467-487.

Table 1. Age level of the patients

\begin{tabular}{|c|c|c|}
\hline \multirow{2}{*}{ Age Level } & \multicolumn{2}{|c|}{ Gender } \\
\cline { 2 - 3 } & Male & Female \\
\hline Total patients & 20 & 20 \\
\hline Mean & 24.2 & 24.55 \\
\hline Std.deviation & 2.01 & 2.50 \\
\hline
\end{tabular}

Table 2. Education level of the patients

\begin{tabular}{|c|c|c|c|}
\hline \multirow{2}{*}{ Education } & \multicolumn{2}{|c|}{ Gender } & \multirow{2}{*}{ Total } \\
\cline { 2 - 3 } & Male & Female & \\
\hline Diploma & 2 & 0 & \\
\hline Bachelor's level Students & 18 & 20 & 38 \\
\hline Total & 20 & 20 & 40 \\
\hline
\end{tabular}

Table 3. Income of the parents of patients

\begin{tabular}{|c|c|c|c|c|}
\hline \multicolumn{2}{|c|}{} & \multicolumn{2}{|c|}{ Gender } & \multirow{2}{*}{ Total } \\
\cline { 2 - 5 } Income of the parents & Male & Female & 6 \\
\cline { 2 - 5 } & 60 up to $200 \$$ & 5 & 1 & 23 \\
\cline { 2 - 5 } & 201up to 400\$ & 6 & 17 & 9 \\
\cline { 2 - 5 } & 401up to 1000\$ & 7 & 2 & 2 \\
\cline { 2 - 5 } & More than 1000\$ & 2 & 0 & 40 \\
\hline
\end{tabular}

Table 4. Result of repeated measures ANOVA

\begin{tabular}{|l|l|l|l|l|l|l|}
\hline Source & $\begin{array}{l}\text { Type III Sum } \\
\text { of Squares }\end{array}$ & DF & Mean Square & F & Sig. & Partial Eta Squared \\
\hline Intercept & 7471308.800 & 1 & 7471308.800 & 7258.937 & .000 & .995 \\
\hline Group & 13158.450 & 1 & 13158.450 & 12.784 & .001 & .252 \\
\hline Error & 39111.750 & 38 & 1029.257 & & & \\
\hline
\end{tabular}


Table 5. Comparison between Score of six Dimensions of Pre and post CBT and WBT in depression patients

\begin{tabular}{|l|l|l|l|l|l|c|c|c|c|c|}
\hline Group & \multicolumn{2}{|l|}{ Pre CBT } & \multicolumn{2}{l|}{ Pre WBT } & \multicolumn{2}{c|}{ Post CBT } & \multicolumn{2}{c|}{ Post WBT } & \multicolumn{2}{c|}{ significant } \\
\hline Variable & Mean & SD & Mean & SD & Mean & SD & Mean & SD & F & Sig \\
\hline Total well-being & 219.20 & 54.67 & 187 & 26.15 & 366.35 & 7.75 & 449.85 & 17.92 & 7258.937 & .001 \\
\hline Autonomy & 32.60 & 8.29 & 32.75 & 1.99 & 65.50 & 1.98 & 82.30 & 1.62 & 9849.95 & .000 \\
\hline Environment & 37.75 & 6.39 & 29.10 & 4.24 & 59.30 & 2.17 & 78.55 & 3.51 & 10661.39 & .000 \\
\hline Positive relation & 38.65 & 11.42 & 26.60 & 11.32 & 70.35 & 3.82 & 71 & 6.23 & 2657.756 & .007 \\
\hline Purpose in life & 32.15 & 7.32 & 39.60 & 5.87 & 55.40 & 3.74 & 75 & 5.08 & 6019.404 & .000 \\
\hline Personal growth & 38.40 & 11.76 & 28.70 & 8.10 & 65.25 & 3.80 & 66.45 & 6.03 & 3670.931 & .014 \\
\hline Self acceptance & 39.65 & 12.81 & 30.25 & 5.89 & 51 & 2.02 & 76.55 & 2.39 & 3622.439 & .000 \\
\hline
\end{tabular}

Table 6. Cohen's Effect Size

\begin{tabular}{|c|c|c|}
\hline & CBT Group & WBT Group \\
\hline Cohen's $\boldsymbol{d}$ & 3.7688227349324186 & 11.72602969365531 \\
\hline $\begin{array}{c}\text { Cohen's r } \\
\text { (effect size) }\end{array}$ & 0.8833280095119671 & 0.9857643751369111 \\
\hline
\end{tabular}

Table 7. Correlation between post PWB and post BDI

\begin{tabular}{|c|c|c|c|}
\hline \multirow{2}{*}{} & sum_post_pwb & sum_BDI_post \\
\hline \multirow{3}{*}{ sum_post_pwb } & $\begin{array}{c}\text { Pearson } \\
\text { Correlation }\end{array}$ & 1 & $-.570(* *)$ \\
\cline { 2 - 4 } & Sig. (2-tailed) &. & .000 \\
\cline { 2 - 4 } & $\mathrm{N}$ & 40 & 40 \\
\hline \multirow{2}{*}{ sum_BDI_post } & $\begin{array}{c}\text { Pearson } \\
\text { Correlation }\end{array}$ & $-.570(* *)$ & 1 \\
\cline { 2 - 4 } & Sig. (2-tailed) & .000 &. \\
\hline Total & $\mathrm{N}$ & 40 & 40 \\
\hline
\end{tabular}

* Correlation is significant at the 0.01 level (2-tailed)

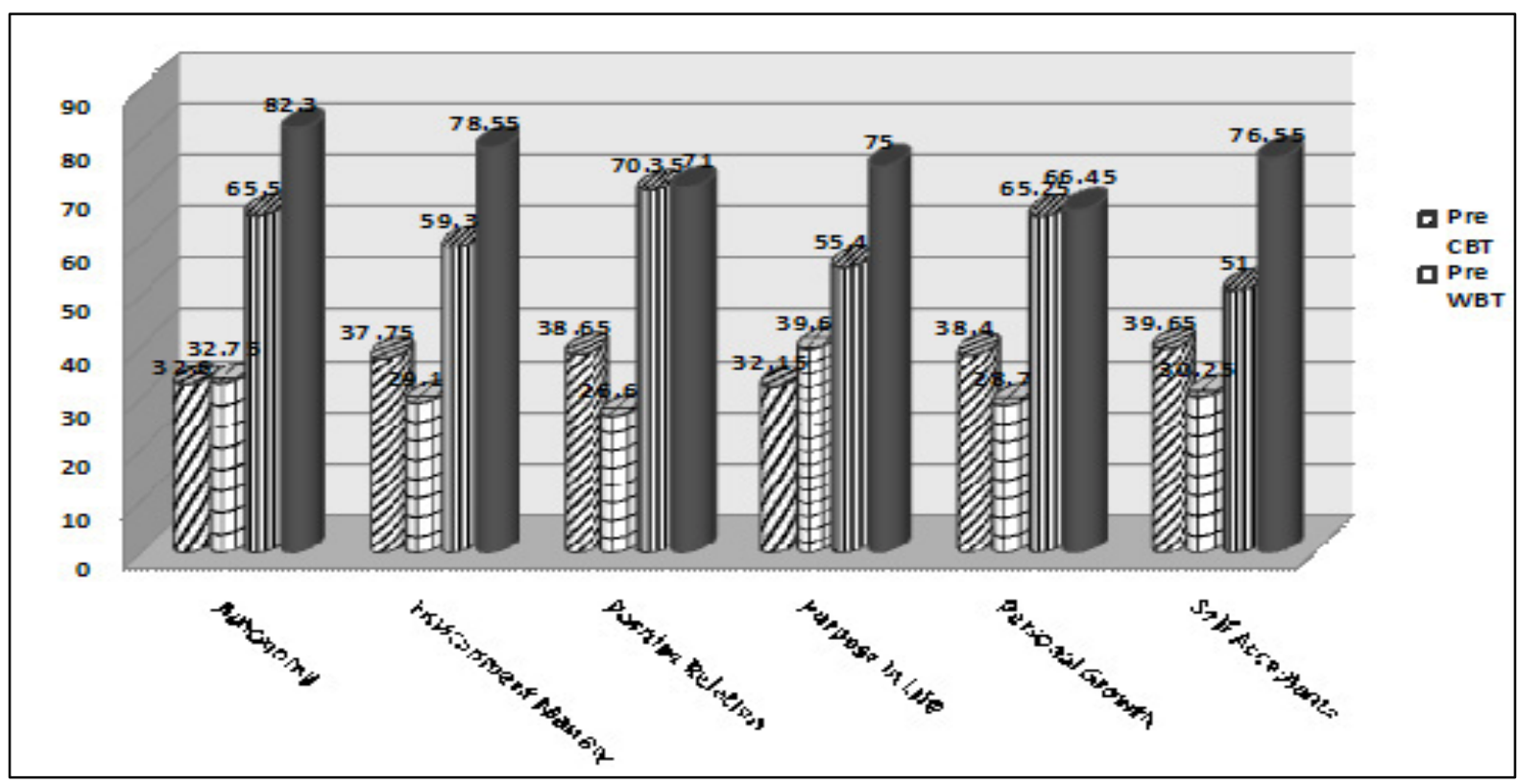

Chart 1. The Differences between Score of six Dimensions of Pre and Post CBT and WBT in depression patients 